\title{
Turbulence fluxes and variances measured with a sonic anemometer mounted on a tethered balloon
}

\author{
Guylaine Canut $^{1}$, Fleur Couvreux ${ }^{1}$, Marie Lothon ${ }^{2}$, Dominique Legain $^{1}$, Bruno Piguet $^{1}$, Astrid Lampert $^{3}$, \\ William Maurel ${ }^{1}$, and Eric Moulin ${ }^{1}$ \\ ${ }^{1}$ CNRM-GAME (Météo-France and CNRS), Toulouse, France \\ ${ }^{2}$ Laboratoire d'Aerologie, University of Toulouse, CNRS, Toulouse, France \\ ${ }^{3}$ Institute of Flight Guidance, TU Braunschweig, Hermann-Blenk-Str. 27, 38108 Braunschweig, Germany \\ Correspondence to: Guylaine Canut (guylaine.canut@meteo.fr)
}

Received: 8 December 2015 - Published in Atmos. Meas. Tech. Discuss.: 18 January 2016

Revised: 16 August 2016 - Accepted: 17 August 2016 - Published: 6 September 2016

\begin{abstract}
This study presents the first deployment in field campaigns of a balloon-borne turbulence probe, developed with a sonic anemometer and an inertial motion sensor suspended below a tethered balloon. This system measures temperature and horizontal and vertical wind at high frequency and allows the estimation of heat and momentum fluxes as well as turbulent kinetic energy in the lower part of the boundary layer. The system was validated during three field experiments with different convective boundary-layer conditions, based on turbulent measurements from instrumented towers and aircraft.
\end{abstract}

\section{Introduction}

The atmospheric boundary layer (ABL) is the lowest part of the atmosphere and hosts turbulent processes responsible for the transfer of heat, moisture and momentum between the surface and the free troposphere. This turbulence is produced by dynamical instabilities due to wind shear or with convective plumes generated by solar heating of the surface. Turbulence in the ABL and its impact on mean thermodynamical variables such as temperature, water vapour mixing ratio and wind can be estimated via the turbulent fluxes. In this paper we focus on sensible heat fluxes and momentum fluxes as well as variances and turbulent kinetic energy.

The observation of these turbulence processes raises specific problems because the phenomena involve fine temporal (from a few tenths of a second to a few minutes) and spatial scales (in the order of metres or tens of metres). Rapid sensors may be available on instrumented towers for most variables (temperature, humidity, wind), but at altitude highfrequency measurements are limited, and the instruments to measure turbulence are mounted mainly on research aircraft.

A large number of field campaigns (SHEBA: Utall et al., 2002; IHOP: Weckwerth et al., 2004; AMMA: Janicot et al., 2008; COPS: Wulfmeyer et al., 2008) carried out in recent years have provided observations that sample vertically the turbulent fluxes in the boundary layer, such as heat and momentum fluxes. The two main platforms used are the instrumented mast and research aircraft. These two very different tools sample temporal and spatial variability concerning the flow. The two points of view are complementary to the study of turbulent boundary-layer processes. Recently, studies with remotely piloted aircraft systems (RPASs) (Martin et al., 2014) have shown the capability of this small and light platform to measure turbulent heat fluxes at altitude.

Fixed-point tower measurements have largely been used to provide useful characterisation of heat fluxes above the surface layer (e.g. Kaimal et al., 1976; Angevine et al., 1998). This platform permits a temporal sampling of the turbulence. However, these measurements are limited in height, with only a few towers reaching more than $100 \mathrm{~m}$. Towers with heights exceeding $50 \mathrm{~m}$ are practically non-portable, which makes them inappropriate for deployment in a field campaign. At altitude, previous studies (Lenschow and Stankov, 1986; Saïd et al., 2010) used instrumented aircraft to measure turbulent heat flux. Aircraft are costly and have constraints: they have a minimal flight altitude. Their relative air speed also imposes the use of fast-response instruments in order to 
measure variations at physical scales equivalent to the ones measured from a fixed location. However, there is no other platform which allows for in situ sampling of the turbulence in such a way from aircraft, from $100 \mathrm{~m}$ a.g.l. to a height of several kilometres, and covering large areas of several tens or hundreds of kilometres. The use of RPASs adds a very interesting and complementary approach, with, for example, lower costs, easier operations, and low-altitude exploration. The range of the scaled probe is however usually much lower than with an aircraft.

The tethered balloon is an intermediate platform between the fixed tower and the aircraft. It allows the sampling of the atmosphere up to $800 \mathrm{~m}$ from various locations. From the point of view of measurement it can be considered a tower which moves vertically, therefore providing a temporal view of the atmospheric processes. However, to quantify turbulence with the tethered balloon it is necessary to correct its motion with similar methods to those used for aircraft or RPASs. This platform has been used in studies since the 1970s (Morris et al., 1975; Kaimal et al., 1976; Ogawa and Ohara, 1982; Muschinski et al., 2001), but it has mainly been used to study mean thermodynamical measurements. Lapworth and Mason (1988) developed a system with a turbulence probe composed of a Gill propeller anemometer attached to the tethering cable of a balloon. The authors used inclinometers and magnetometers at a frequency of about $1 \mathrm{~Hz}$ in order to determine the probe sensor orientation. The system weighed roughly $10 \mathrm{~kg}$. Recently, Balsley (2008) developed a tethered lifting system that could be mounted above a kite or a balloon. The turbulence package embarked on this system record high-frequency and lowfrequency fluctuations of temperature and velocity with the fast-response cold-wire temperature and hot-wire velocity sensors respectively.

Today, 3-D, fast-response ultrasonic anemometers instruments are commonly available, and technological advances have resulted in the availability of compact and reasonably low priced attitude- and motion-measuring units from commercial manufacturers. It has become second nature to combine both systems in order to obtain wind measurements in new situations. Belušić et al. (2014) explore, for example, the performance of such devices mounted on a car for mean wind and turbulence measurements. A team from the US Environmental Protection Agency's Office of Research and Development used similar sensors mounted on a tethered balloon in order to estimate mean wind speed and direction at altitude, and the goal of present work is to prove that these devices are fully able to measure turbulence in the ABL.

A detailed examination of the general applicability of an instrumented balloon for measuring ABL turbulent fluxes has not been previously undertaken. The objective of this study is to demonstrate that an instrumented balloon can be used for measurements of heat flux, momentum flux and the turbulent kinetic energy within the ABL. The major advantage of tethered balloons is their potential to provide flux measurements at various vertical heights covering a part of the vertical extent of the boundary layer. In field campaigns, it is therefore a complementary tool for aircraft and towers and, in the future, RPASs for the measurement of temporal and spatial scales.

The turbulence tethered sonde presented here is designed to measure variance of wind, heat and momentum fluxes. The paper is structured as follows. Firstly, we will describe the general architecture of the system, the sensor characteristics and the motion correction. Sections 3 and 4 are dedicated to the validation close to the surface and within the boundary layer using conventional data from towers and aircraft. In Sect. 5, we will explore the capability of the system to study the turbulence structure in the context of the transition of late afternoon. Conclusions are provided in Sect. 6.

\section{Overview of the system}

The turbulence probe, denoted TS from now on, consists of a sonic anemometer and an inertial motion sensor attached to the cable of a tethered balloon. This part of the paper describes the general architecture of the system, i.e. the balloon used and the turbulence probe. The aim is to develop a simple device that can be easily deployed in different field campaigns. The platform combines fast and slow sensors to quantify mean and turbulent processes.

\subsection{Sensor characteristics}

In this study we used the Vaisala $7 \mathrm{~m}^{3}$ tethered balloon (the model used was the Vaisala TTB327 (L $4.6 \mathrm{~m} \times \mathrm{H}$ $1.84 \mathrm{~m} \times \mathrm{W} 1.84 \mathrm{~m} ; 3.1 \mathrm{~kg}$ ) inflated with helium. The balloon is a zeppelin-shaped aerostat restrained by a cable attached to the ground. The cable has an electric winch used to raise and lower the balloon. The mass of the cable is $0.5 \times 10^{-3} \mathrm{~kg} \mathrm{~m}^{-1}$ and the maximum height of flights that can be reached depends on atmospheric conditions (wind speed). We have never tested this system at an altitude higher than $1000 \mathrm{~m}$.

The turbulence tethered sonde can be attached to a wide variety of balloons; a specific balloon is not necessary for the purpose. The instrument package consists of a slow measurement instrument, a $1 \mathrm{~Hz}$ Vaisala tethered sonde (TTS111 model) mounted below the tethered line (at approximatively $6 \mathrm{~m}$ below the balloon) and a fast measurement instrument, which is suspended $8 \mathrm{~m}$ below the balloon in order to avoid wind flow distortion due to the balloon. The TS is attached to the cable with a horizontal pivot. The advantage is that yaw movements of the TS are limited. The Vaisala commercial probe provides slow measurements of temperature, humidity, pressure, wind speed and direction, and it is able to transmit $1 \mathrm{~Hz}$ data to the ground using a radio link. This probe is mainly used to monitor the wind at flight altitude in real time, so as to respect safety requirements. In our case, the maximum permitted wind speed is $12 \mathrm{~m} \mathrm{~s}^{-1}$, following the balloon manufacturer's specifications. 
Table 1. Accuracy of the MTi-G instrument as given by the manufacturers.

\begin{tabular}{ll}
\hline Parameter & GPS-INS \\
\hline Pitch, roll & $0.8^{\circ}$ \\
Heading & $0.5^{\circ}$ \\
$u, v$ & $0.1 \mathrm{~m} \mathrm{~s}^{-1}$ \\
$w$ & $0.1 \mathrm{~m} \mathrm{~s}^{-1}$ \\
Position & $2.5 \mathrm{~m}$ \\
\hline
\end{tabular}

The TS is based on a commercial sonic anemometer (Gill WindMaster Pro, Fig. 1a) which provides measurements of three-dimensional wind and sonic temperature at $10 \mathrm{~Hz}$. Kaimal and Gaynor (1990) showed that the sonic temperature can be used as a good proxy of the virtual temperature. The thermo-anemometer allows the connection of other sensors to their own analogue inputs. A fast-response thin wire allows the measurement of air temperature fluctuations and standard pressure and temperature sensors provide slow reference measurements. An off-the-shelf coupled inertial-GPS motion and attitude sensor (MTi-G at $10 \mathrm{~Hz}$ from Xsens, Fig. 1b) was added in order to correct anemometer movements. The accuracy of the parameters provided in the MTi$\mathrm{G}$ is given in Table 1. The data acquisition system was built in our laboratory. It is based on a PIC24F microcontroller, and it records data emerging from both sensors via two RS232 connections onto two SD cards. The total mass of the system is $2 \mathrm{~kg}$ including batteries $(0.3 \mathrm{~kg})$. The sonic anemometer represents half of the mass $(1 \mathrm{~kg})$, whereas the GPS-INS weights only $0.15 \mathrm{~kg}$. The mean advantage of the instrumentation proposed here is the use of a sonic anemometer instead of a propeller anemometer, which has a greater sampling frequency and a lower weight $(2 \mathrm{~kg}$ instead of the $10 \mathrm{~kg}$ for the Lapworth platform; Lapworth and Mason, 1988). The decrease in weight was made possible by the miniaturisation of sensors in recent years. The system can run for $4 \mathrm{~h}$ powered by eight $1.2 \mathrm{~V}, 2700 \mathrm{mAh}$ NiMH batteries.

\subsection{Motion correction}

The off-the-shelf coupled inertial-GPS motion and attitude sensor is used to measure the balloon's position and speed, as well as the orientation of the sonic anemometer. It is fixed to the platform $40 \mathrm{~cm}$ above the sonic anemometer.

Linear and rotational speeds provided by the INS are used to compute the speed of the platform in the coordinate system of the sonic anemometer. This means that the wind vector in the platform coordinate system is the simple vector difference between the sonic and GPS-INS velocities:

$V_{\text {platform }}=V_{\text {sonic }}-V_{\mathrm{INS}}$,

where $V_{\text {platform }}$ is the wind vector in the platform coordinate system, $V_{\text {INS }}$ is the GPS-INS motion vector, and $V_{\text {sonic }}$
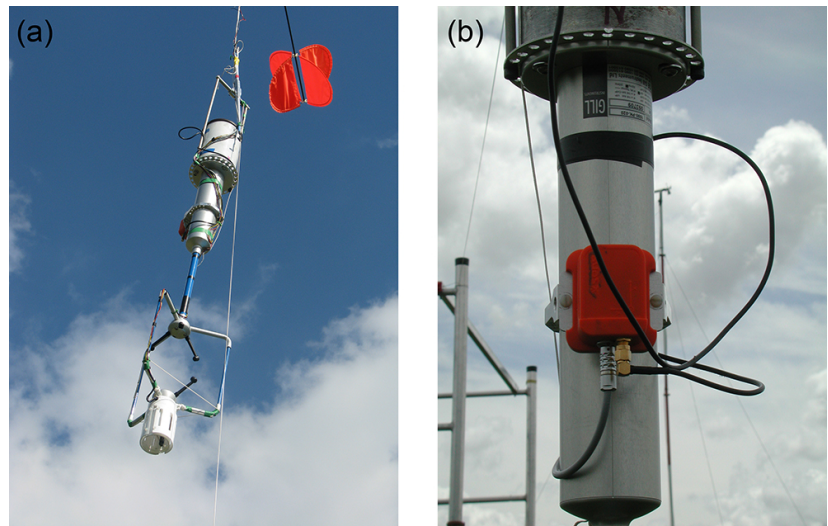

Figure 1. Image of the turbulence tethered sonde: (a) the sonic anemometer and the electronic system and (b) the inertial motion sensor.

is the platform-relative flow vector measured by the sonic anemometer.

The INS measures angles of attitude (rolls, pitch and yaw angles), allowing us to rotate the wind vector measured in the platform coordinate system in the meteorological coordinate system. Geo-referenced $u, v$ and $w$ wind components are then calculated from frequently adopted equations of Lenschow (1986).

A series of tests were conducted in order to assess the capability of this system to remove the motion of the sonic anemometer and to accurately compute wind fluctuations at a frequency suitable for turbulence studies. In June 2010 the system was suspended below a gantry and left oscillating starting at $30^{\circ}$ from the vertical. We verified that the oscillation was invisible in the computed wind. Due to different processing times in both instruments, the recorded data cannot be considered to be perfectly synchronous. We empirically determined the delay as the value which minimises the variance of the computed wind during the large oscillations described above. Data recorded during real flights showed that the oscillation amplitude is smaller than that which was measured on the ground: inclination very rarely exceeded $10^{\circ}$ (whatever the axis). When the probe is suspended below the balloon, however, it is not strictly constrained on the vertical axis: we observed a great variation in the heading (the angle of the horizontal plane between the north and the first axis of the attitude and motion sensing system and the north), with rotation rates reaching (and sometimes even exceeding) half a revolution per second. An example of this behaviour is shown in Fig. 2, which demonstrates that the system is able to correct this twisting motion: the heading changes rapidly, the rotation speed magnitude reaches almost $1 \mathrm{rps}\left(-6 \mathrm{rad} \mathrm{s}^{-1}\right.$ at 15:33:33), the measured wind component flips signs accordingly (panel 3, at 15:33:28; the second component varies from 4 to $-4 \mathrm{~m} \mathrm{~s}^{-1}$ ), and the fluctuation of the computed wind remains limited, between 0.5 to $1 \mathrm{~m} \mathrm{~s}^{-1}$ (bottom panel). 


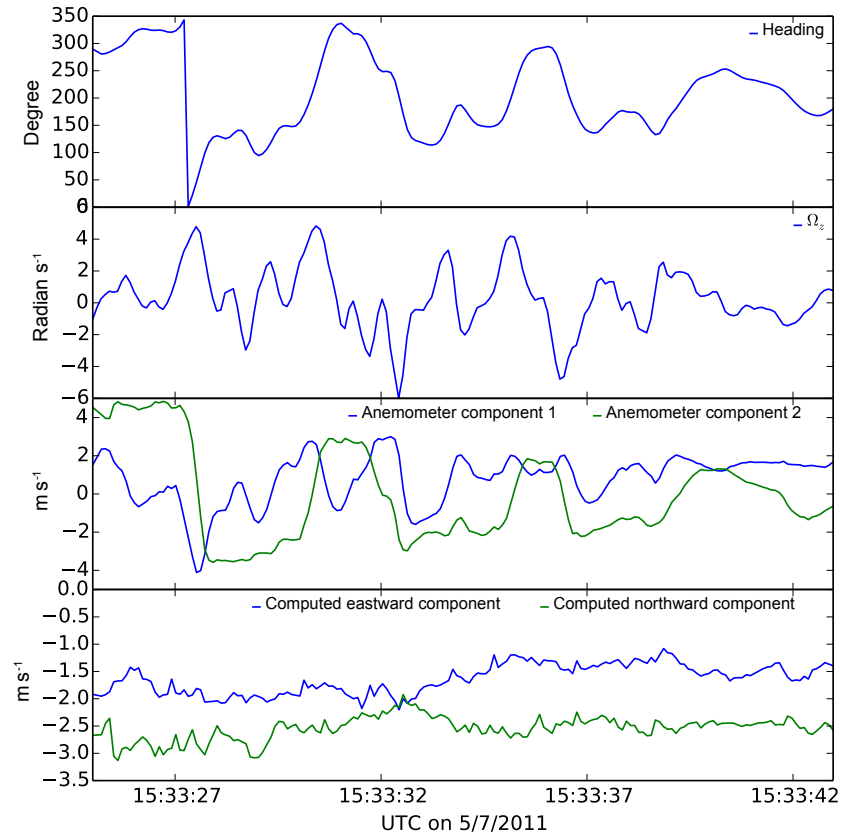

Figure 2. Time series of sensor orientation and wind during $20 \mathrm{~s}$ of a flight in the BLLAST campaign (5 July 2011). Panel's content, from top to bottom, is as follows: (top) heading - angle between the north and the first horizontal axis of the MTi-G; (upper middle) rotation rate along the $z$ axis of the MTi-G; (lower middle) two components of the wind measured by the WindMaster anemometer along its $x$ and $y$ axis; and (bottom) northward and eastward components of the computed wind.

As part of a routine monitoring, for each flight we compared the power spectra density (PSD) of the raw and corrected wind components. Figure 3 shows an example during the test flight in Lannemezan, on 31 August 2010 between 14:00 and 15:00 UTC. This example clearly illustrates that the motion correction allows the removal of the peak linked to the modal oscillation frequency of the system at $0.2 \mathrm{~Hz}$.

\section{Validation close to the surface}

In order to check the validity of the high-frequency measurements obtained by the TS, measurements are compared with those of a three-dimensional sonic anemometer fixed on masts and installed during three experimental campaigns between 2010 and 2013. Note that our goal is to make sure that the turbulence statistics are comparable, but not to make point-to-point comparisons. Ideally, for comparison with fixed points on a tower, flying at constant altitude close to the tower is desirable. The horizontal distance between TS and the position of the towers was less than $200 \mathrm{~m}$. The first two campaigns took place in the summers of 2010 and 2011 at the BLLAST (Lothon et al., 2014) experimental site using a tower equipped with a three-dimensional sonic anemometer (CSAT, Campbell Scientific Inc, Logan, UT, USA) at
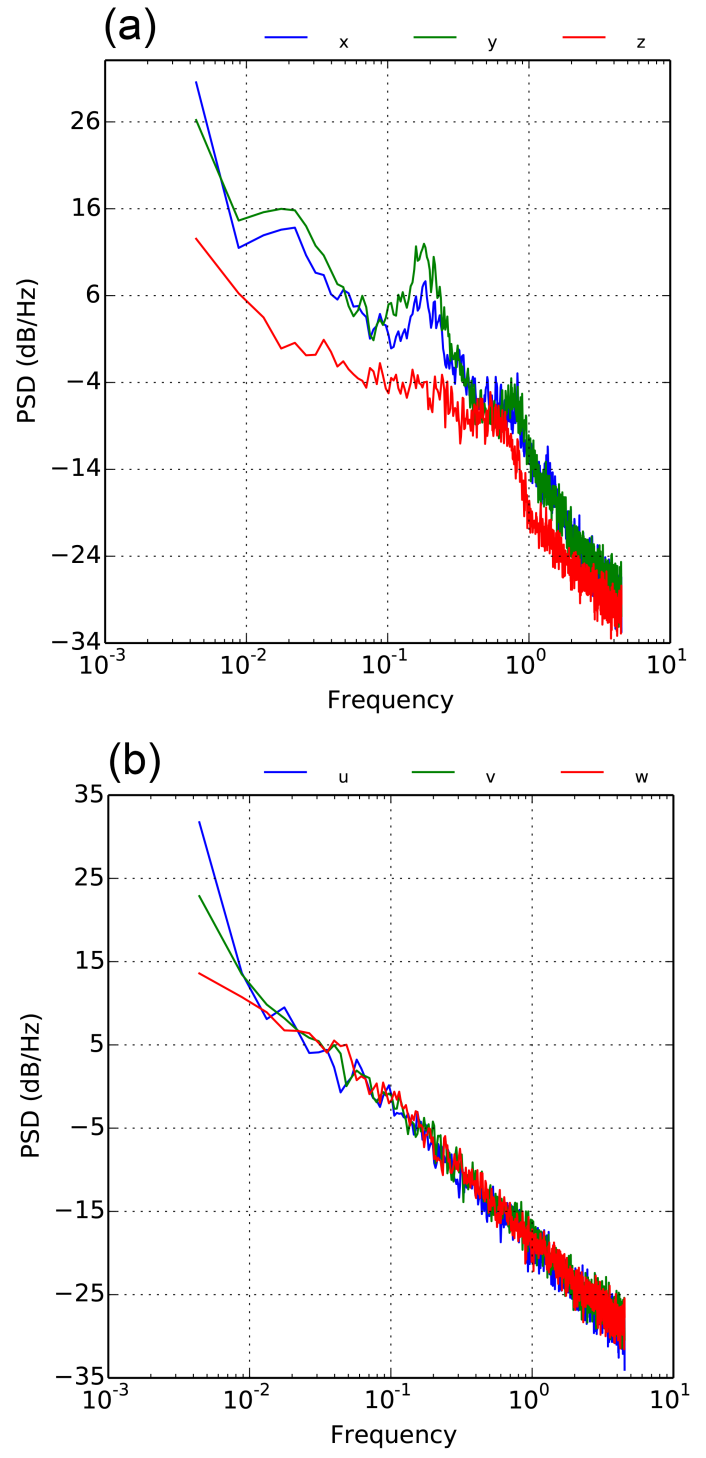

Figure 3. Power spectra density for (a) the raw $u, v$ and $w$ provided by the sonic anemometer and (b) the computed $u, v$ and $w$ after motion correction.

$60 \mathrm{~m}$. The third took place at Bourges (France) at a French military site which was equipped with a tower with threedimensional sonic anemometer (GILL HS 3-Axis, Gill Instruments Limited, Lymington, Hampshire, UK) at $30 \mathrm{~m}$. For every day and hours considered here, the atmospheric boundary layer was convective and under clear skies. Only the campaign in August 2010 at the BLLAST site was entirely dedicated to the validation of the TS. No scientific constraints were therefore imposed. Indeed, for 2 days, the TS flew at a fixed height corresponding to the instrumented level of the mast. Concerning the other two campaigns, the TS did not remain at the same height for the whole of each day. Therefore, we only selected measurement periods when the TS was at a similar level to the fixed sonic anemometer. 
(a)

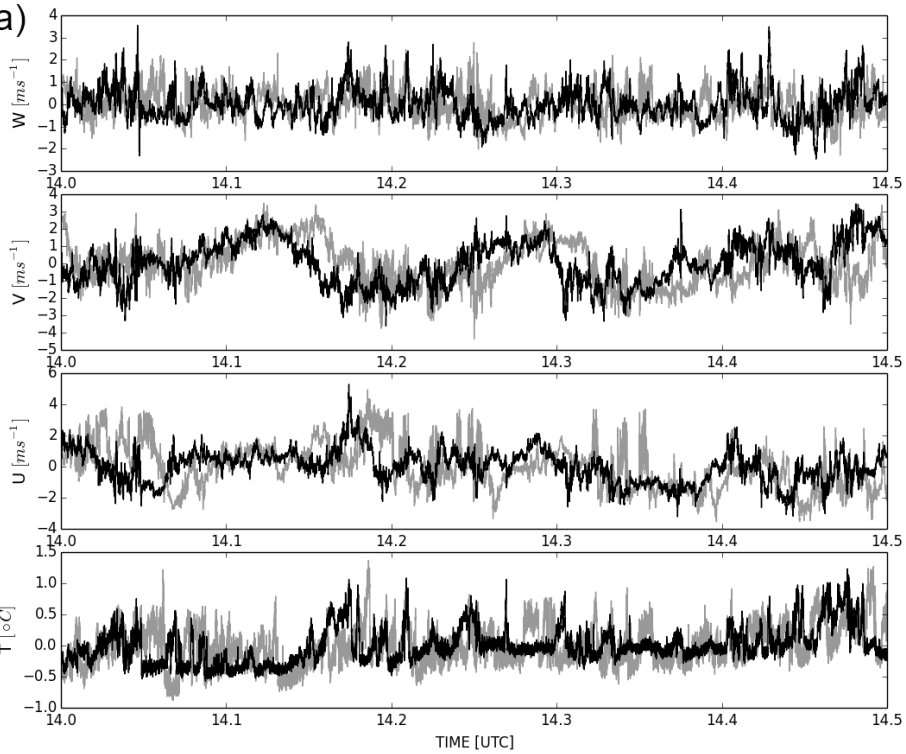

(b)

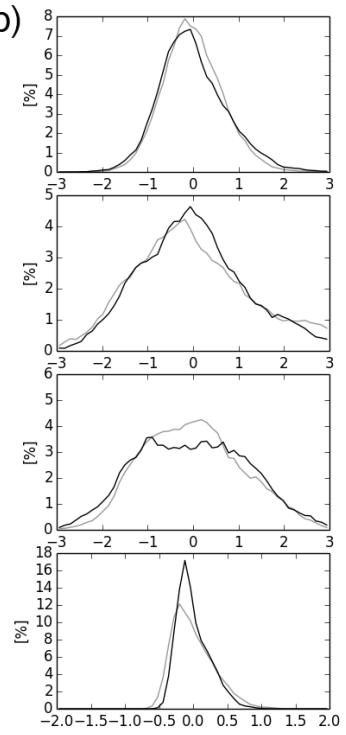

(c)

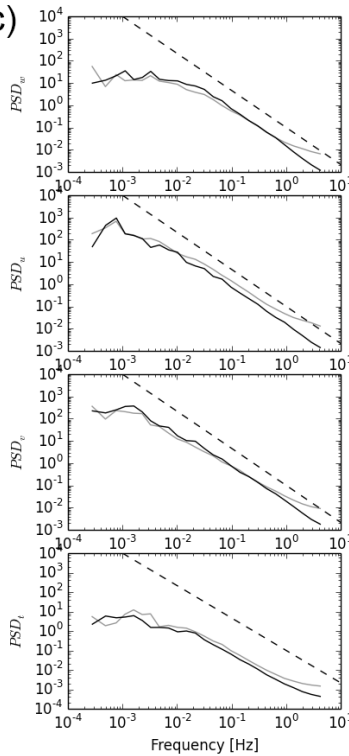

Figure 4. Comparison of $w^{\prime}, v^{\prime}, u^{\prime}$ and $t^{\prime}$ measured by a tethered-balloon probe (black) and a sonic anemometer (grey) fixed onto a tower nearby for (a) $10 \mathrm{~Hz}$ time series for $30 \mathrm{~min}$, (b) fluctuation distribution of a $2 \mathrm{~h}$ sample, and (c) power spectra density corresponding to the same sample.

On average, the time series recorded during these different campaigns (after motion correction was applied) exhibit a large coherence with each other, despite the aforementioned spatial differences between the tower and the TS. A degree of horizontal offset between the balloon and tower is unavoidable due to the distance between both sites.

We hereafter denote $u^{\prime}, v^{\prime}, w^{\prime}$ and $t^{\prime}$ the fluctuations in longitudinal wind, transverse wind, vertical wind and potential temperature respectively. Fluctuations $x^{\prime}$ of a variable $x$ are computed as $x^{\prime}=x-\bar{x}$, where $\bar{x}$ is the mean over a chosen period. An example of the high-frequency measurements of fluctuations of the three-dimensional winds, and potential temperature is shown in Fig. 4a for a 30 min sample on 31 August 2010. The two records do not overlap perfectly, which is expected with fast measurements made $200 \mathrm{~m}$ apart, but they do show the same turbulence structures quite nicely. The comparison of the turbulence statistics between both samples is based on the integral scales, the distribution of the fluctuations, the density energy spectra and the secondorder moments. We calculated the integral length scales defined from the autocorrelation function of longitudinal wind, transverse wind, vertical wind and potential temperature. Table 2 summarises the different estimates. For $w$, we obtained 81 and $84 \mathrm{~m}$ respectively for the tower and the tethered balloon. The values differ only slightly, indicating similar turbulence sampled by both instruments.

However, the range of the fluctuations of $u, v, w$ and $t$ are similar between the TS and the data from the fixed sonic anemometer. The distribution of the fluctuations recorded during a $2 \mathrm{~h}$ period at midday is also presented in Fig. $4 \mathrm{~b}$.
Table 2. Integral length scale of $w, u, v$ and $t$ in Lannemezan, on 31 August 2010 between 12:00 and 14:00 UTC.

\begin{tabular}{lllll}
\hline & $w$ & $u$ & $v$ & $t$ \\
\hline$L_{\text {int }}$ TS & 84 & 510 & 300 & 321 \\
$L_{\text {int }}$ mast & 81 & 552 & 360 & 311 \\
\hline
\end{tabular}

Between both instruments a very similar distribution of all the fluctuations is obtained with the same shape and amplitude for all parameters here considered. Figure $4 \mathrm{c}$ presents a comparison of power spectra for $2 \mathrm{~h}$ measurements at midday for wind components and the potential temperature derived from both systems. The comparison between the TS spectra and the tower spectrums is generally quite good, and both spectra show the expected $-5 / 3$ slope at higher frequencies.

From those fluctuation measurements at $10 \mathrm{~Hz}$, several second-order moments can be determined for the use of the eddy correlation method. The following subsection presents the validation of variances of the three components of the wind, the temperature and the turbulent sensible heat flux.

\subsection{Variance}

Variance is commonly used for studying certain thermodynamical parameters in the boundary layer as a measure of the intensity of the turbulence. Figure $5 \mathrm{a}$ and $\mathrm{b}$ present the comparison of the variance of vertical velocity and temperature calculated every $20 \mathrm{~min}$ for $10 \mathrm{~h}$ between the fixed sonic anemometer on the mast and the TS. The dashed line rep- 
Table 3. The correlation coefficient between TS and sonic anemometer on the mast for variances of the three components of wind, potential temperature, sensible heat and momentum kinematic fluxes. $r_{2010}^{2}$ concerns the dedicated campaign in 2010 and $r_{\text {BLLAST }}^{2}$ and $r_{\text {BOURGES corresponds to BLLAST and Bourges }}^{2}$ field campaigns respectively.

\begin{tabular}{lccccccc}
\hline & $\sigma_{w}^{2}$ & $\sigma_{t}^{2}$ & $\sigma_{u}^{2}$ & $\sigma_{v}^{2}$ & $w^{\prime} t^{\prime}$ & $w^{\top} u^{\prime}$ & $w^{\top} v^{\prime}$ \\
\hline$r_{2010}^{2}$ & 0.88 & 0.94 & 0.80 & 0.84 & 0.92 & 0.81 & 0.80 \\
$r_{\text {BLLAST }}^{2}$ & 0.85 & 0.93 & 0.82 & 0.84 & 0.87 & 0.80 & 0.76 \\
$r_{\text {BOURGES }}^{2}$ & 0.90 & 0.90 & 0.85 & 0.80 & 0.88 & 0.84 & 0.82 \\
\hline
\end{tabular}

resents the difference in altitude between both instruments. Note that the difference in altitude of the tethered balloon varies from a few metres to tens of metres due to turbulent motions of the atmosphere. For this reason, the variation in altitude around $60 \mathrm{~m}$ is greater in the middle of the day, when convection is at its strongest. During the afternoon, when the difference in altitude is often greater than $10 \mathrm{~m}$, the values in $\sigma_{w}^{2}$ are higher for the TS, whilst the values in $\sigma_{t}^{2}$ are lower for the TS. This is consistent with the behaviour of a convective $\mathrm{ABL}$ in which fluctuations of temperature are greater near the surface, whilst fluctuations of vertical wind are greater in the middle of the ABL. The largest discrepancy was obtained between TS and the tower when the altitude difference between both was the greatest. Regarding the variances of the horizontal components of the wind (not shown here), no trend is observed between the two instruments. After 16:00 UTC for the day represented in the figure, the values of the variances obtained are usually similar between both instruments when the TS is positioned at exactly the same level as the fixed sonic anemometer. Table 3 summarises the correlation coefficients computed for the different variances measured by both instruments during the three field campaigns. For the 2010 campaign in Lannemezan, these correlation coefficients are calculated based on the data from 30 and 31 August 2010 between 08:00 and 20:00 UTC, i.e. more than $20 \mathrm{~h}$ of data. For $\sigma_{u}^{2}, \sigma_{v}^{2}, \sigma_{w}^{2}$ and $\sigma_{t}^{2}$ the values are close to unity and confirm the coherence between both instruments. For the two other campaigns the values are similar to the values obtained in 2010 for all the variances.

\subsection{Fluxes}

Eddy covariance (Kaimal and Businger, 1963; Stull, 1988) is a well established method for the direct measurement of the vertical exchange of heat and momentum fluxes in the atmosphere. The vertical turbulent flux $\left(F_{S}\right)$ is provided by the covariance between fluctuations of vertical wind velocity $\left(w^{\prime}\right)$ and those of the tracer of interest (noted $s$ below and represented in this study by potential temperature $t$, or horizontal wind component $u$ and $v$ ) for the averaging period
$\left(T_{m}\right)$ :

$F_{S}=\frac{1}{T m} \int_{0}^{T_{m}} w^{\prime} s^{\prime} \mathrm{d} x$.

$F_{u}$ and $F_{v}$ thus denote the momentum fluxes, and $F_{t}$ the buoyancy flux. $T_{m}=30 \mathrm{~min}$ and a measurement frequency of $10 \mathrm{~Hz}$ are generally considered acceptable for tower-based instruments to be able to capture the frequency bandwidth of eddy sizes contributing to the flux (Aubinet et al., 2012). To ensure that the averaging period is long enough we calculate the ogive (not shown here) using the cumulative integral of the co-spectrum of the turbulent flux starting at the highest frequencies: a period greater than $16 \mathrm{~min}$ is determined as sufficient for the calculation of the turbulent fluxes. Therefore, in the following, we chose $20 \mathrm{~min}$ for the computation of the fluxes with both tower and TS data. Figure $5 \mathrm{c}$ shows the comparison between the TS and the fixed sonic anemometer for the sensible heat flux during $10 \mathrm{~h}$ of measurements. Agreement is satisfactory even if $F_{t}$ seems to be systematically larger for the tower data during the convective period. This is consistent with TS always being positioned above the tower (between 10 and $20 \mathrm{~m}$ ) and a quasilinearly vertical decrease in the sensible heat flux in these atmospheric conditions. For the day in question, correlation coefficients between both datasets are $0.92,0.81$ and 0.8 (Table 3) for $F_{t}, F_{u}$ and $F_{v}$ respectively. More differences are found for $F_{u}$ and $F_{v}$ than for $F_{t}$, but one explanation could be that the flow is distorted by the tower (Miller et al., 1999), which may induce modifications of the fluctuations of zonal and meridional winds. To summarise, Fig. 6 presents the comparison of the turbulent sensible heat fluxes between tower and TS observations for the entire set of available data (63 segments of $20 \mathrm{~min}$ ), including selected periods of BLLAST and BOURGES campaigns for which the tethered balloon flight was located at a similar altitude to the sonic anemometer on the tower for more than $20 \mathrm{~min}$. The maximum altitude difference is $30 \mathrm{~m}$. The range of data is between 0 and $0.2 \mathrm{~K} \mathrm{~m} \mathrm{~s}^{-1}$. The coefficient correlation between TS and fixed sonic anemometer for the sensible heat flux parameter is 0.85 . This value indicates a satisfactory agreement between TS and towers for different places and for moments in the day.

\section{Validation throughout the planetary boundary layer (PBL) depth}

In this section, we use data from aircraft and remotely piloted aircraft systems to look at the behaviour of the TS at altitude while the previous section concentrated on the validation of the turbulent data from TS close to the surface with fixed sonic anemometers. Of the three campaigns in this study, only the BLLAST field campaign offers complementary data for the validation of the TS data above $60 \mathrm{~m}$. 

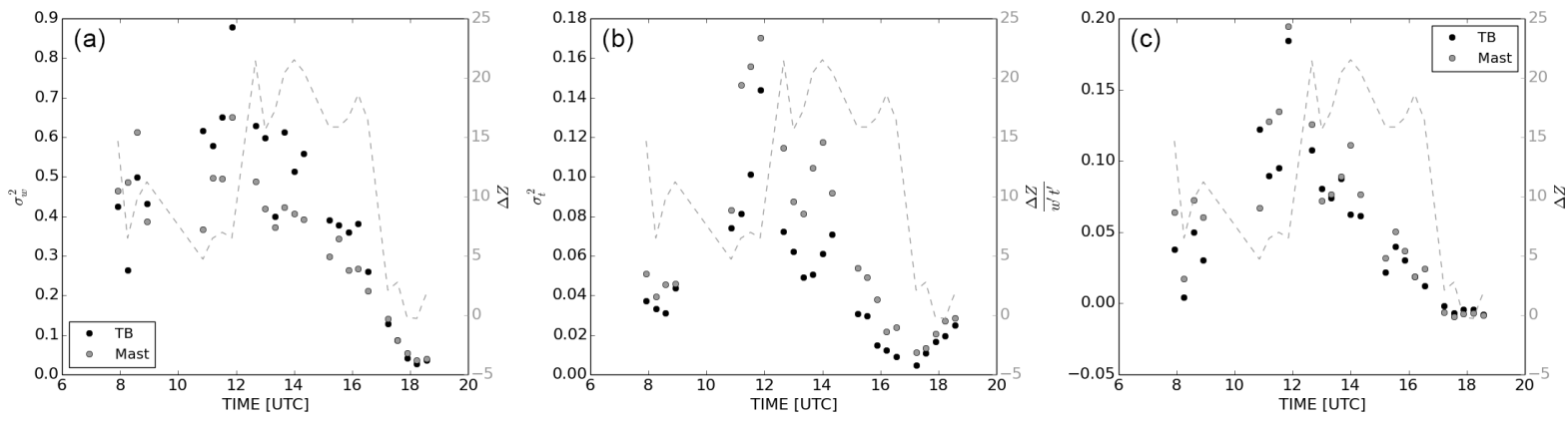

Figure 5. Temporal evolution of turbulent moments measured by the tethered balloon (black) and the tower (grey) on 31 August 2010 : (a) vertical velocity variance, (b) temperature variance and (c) buoyancy flux. The dashed line represents the variation in the altitude of the tethered balloon relative to the $60 \mathrm{~m}$ tower top.

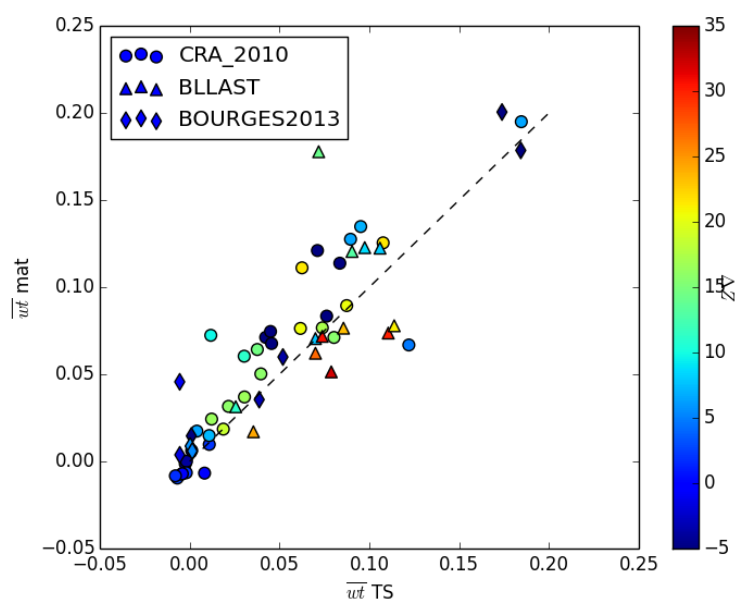

Figure 6. Correlation plot between sensible heat flux obtained by TS and data from towers during three different campaigns at two different places in the summers of 2010, 2011 and 2013. The colour corresponds to the altitude difference between TS and the sonic anemometer on the tower.

The BLLAST field campaign has been described in detail in Lothon et al. (2014). The aim was to comprehend the turbulent processes during the transition at the end of the afternoon, when the boundary layer turns from convective to residual. This campaign brought together many complementary observation devices including remotely piloted airplane systems (RPASs), aircraft, wind profilers, sodar, lidars, tethered balloons and balloon soundings among others, with the objective of achieving an exhaustive description of the dynamical processes in the boundary layer. The campaign documented 11 days with systematic intensification of the observations during the afternoon. It is in this context that the TS was deployed during the 11 intensive observation periods (IOPs). Table 4 summarises the duration of the flights of the TS. Generally, flights began at the beginning of the afternoon and ended before 20:00 UTC. Battery life was not long enough to cover the entire period and the flights were divided into two parts. The altitude of the TS varied according to the different IOPs but remained between 150 and $500 \mathrm{~m}$, corresponding to the first half of the ABL. The French Piper Aztec aircraft from SAFIRE mainly flew in the middle to late afternoon and measured pressure, temperature, moisture, $\mathrm{CO}_{2}$ concentration and 3-D wind at $10 \mathrm{~Hz}$ with a spatial resolution of $3 \mathrm{~m}$ within the ABL (doi:10.6096/BLLAST.PiperAztec.Turbulence). Flights generally included stacked level runs in vertical planes within the ABL in the region of the instrumental site. M2AV (Martin et al., 2014; Wildmann et al., 2014) remotely piloted aircraft systems were deployed for four IOPs with an intensification in flights in the middle to late afternoon. M2AV measured temperature at $100 \mathrm{~Hz}, 3-\mathrm{D}$ wind and humidity at $1 \mathrm{~Hz}$. Flights included straight legs of $1 \mathrm{~km}$ in length at around $300 \mathrm{~m}$ of altitude. In this paper, only the M2AV data from the IOP on 2 July 2011 are used.

\subsection{The turbulent kinetic energy}

Turbulent kinetic energy (TKE) quantifies the intensity of turbulence which controls vertical mixing (Lenschow and Stankov, 1974; André et al., 1978; Lenschow and Stephens, 1980). It is defined as

$\mathrm{TKE}=0.5\left(\sigma_{w}^{2}+\sigma_{u}^{2}+\sigma_{v}^{2}\right)$,

and is one of the common parameters measured by TS, aircraft and M2AV. Depending on the different platforms, integrated times with which to compute TKE can vary. For TS we chose to take $20 \mathrm{~min}$ as determined by the ogive method (see Sect. 3). For aircraft estimation the calculation is made with data recorded along stacked legs of around $40 \mathrm{~km}$ (around $6 \mathrm{~min}$ ). For M2AV we have an estimation for each straight leg of $1 \mathrm{~km}$ length (corresponding to $3 \mathrm{~min}$ ). In order to be consistent with the TS data, an averaging of $20 \mathrm{~min}$ is applied to the M2AV data. Figure 7 presents the comparison between the three platforms. We selected only the data when the difference in altitude between TS and aircraft or M2AV was smaller than $250 \mathrm{~m}$. In convective conditions, TKE presents 


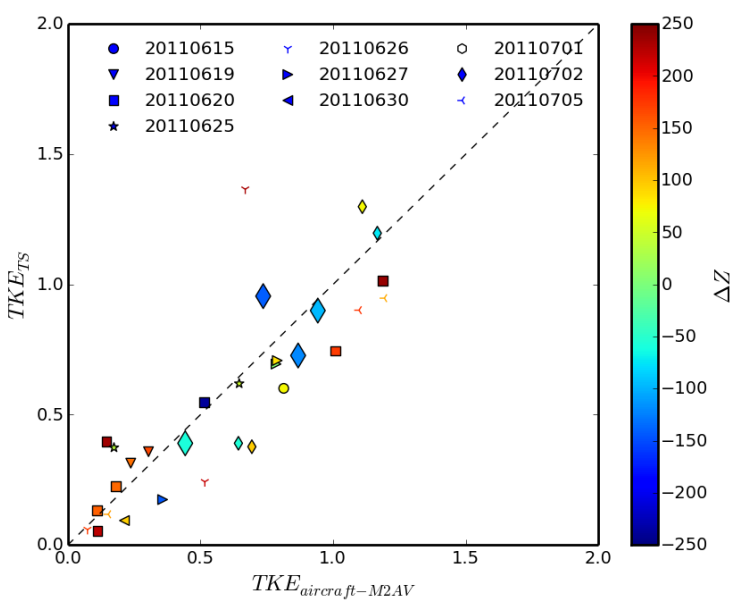

Figure 7. Turbulent kinetic energy measured from tethered balloon ( $y$ axis) as opposed to aircraft or M2AV ( $x$ axis) for 10 IOPs during the BLLAST campaign in June-July 2011. Small symbols are used for aircraft and bigger ones are used for M2AV (for 2 July). The colour corresponds to the altitude difference between TS and aircraft or M2AV.

quasi-constant values in the middle of the $\mathrm{ABL}$, and it is the reason why we are able to compare the TKE observed by the three platforms even if altitudes are not exactly identical. The data set consists of ten different IOPs and presents a large range of values of TKE between 0 and $1.5 \mathrm{~m}^{2} \mathrm{~s}^{-2}$. Mostly, the altitude of the aircraft is above the TS and the contrary when we consider the data from M2AV. The correlation coefficient is close to unity $(r=0.88)$ between the three platforms. This confirms that the estimation of TKE at altitude by TS is reliable.

\subsection{Heat flux}

Unlike the TKE, the sensible heat flux observed in a convective boundary layer presents a linear decrease with height and becomes negative close to the boundary-layer top. This feature makes it difficult to compare data from TS and aircraft when their altitudes differ. In particular, aircraft flight altitude is often located close to the level where the sign of the heat flux changes making uncertain the flux determination by aircraft. When comparing data from the TS during BLLAST with fixed mast data we systematically observe a decrease in the sensible heat flux with altitude. Figure 8 shows an example of the profile of the sensible heat flux obtained in the ABL on 2 July 2011. At two different times, the combination of data from the fixed tower, TS and aircraft shows a decrease in the sensible heat flux with altitude. This does not allow us to directly validate the measurement of sensible heat fluxes, but it at least indicates consistency among the different datasets. In fact, one of the interests here regarding the combination of those complementary platforms is to obtain the vertical structure of the turbulence throughout the PBL.

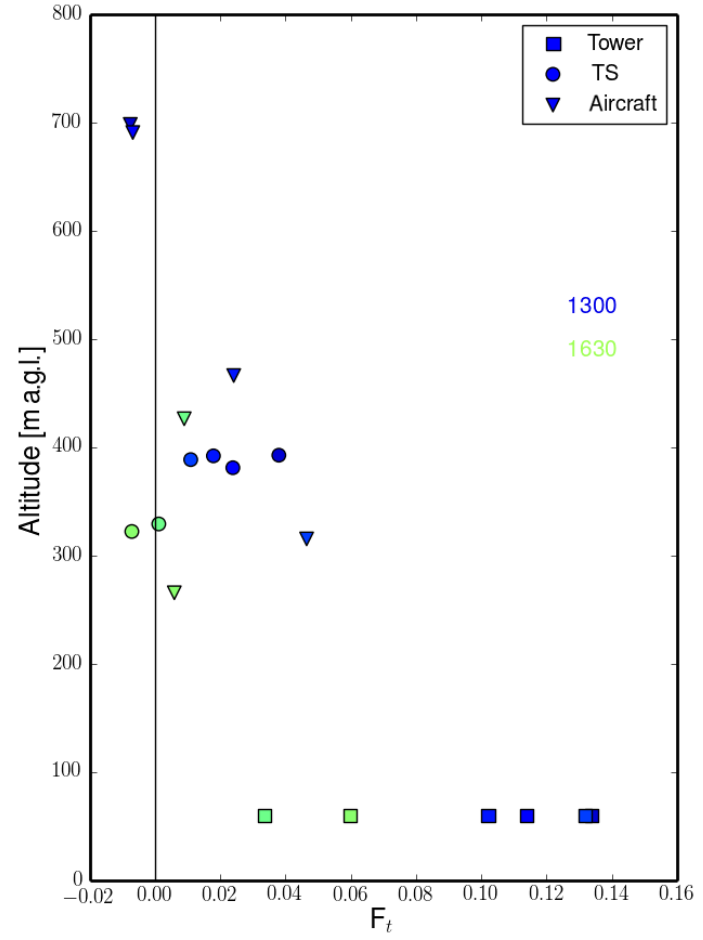

Figure 8. Sensible heat flux profiles obtained with (triangle) aircraft, (circle) TS and (square) sonic anemometer on the $60 \mathrm{~m}$ tower on 2 July 2011 during the BLLAST field campaign. The colour corresponds to the time of day.

\section{The turbulence tethered sonde in the framework of the BLLAST study}

As seen in Sect. 4, during the BLLAST campaign, the TS data have been added to very rich datasets with several levels of instrumented measurements on the $60 \mathrm{~m}$ tower, aircraft flights and RPASs. In this section we will focus more on the evolution of the TKE during the afternoon obtained with the TS.

\subsection{Turbulent kinetic energy}

Figure 9 presents the afternoon evolution of the TKE during the 10 IOPs obtained with aircraft, TS and the tower. Concerning the timing of the decrease in the TKE, we observe a similar behaviour for each day. Up until 16:00 UTC, before TKE starts to decrease, it remains close to $1 \mathrm{~m}^{2} \mathrm{~s}^{-2}$ at the surface (the sonic anemometer is on a tower at $8 \mathrm{~m}$ ) and in the middle of the ABL (between 0.2 and $0.6 z / z i$ with aircraft and TS). However, after 16:00 UTC, when the decrease begins, we can see that the value at $8 \mathrm{~m}$ remains larger than the TKE observed above until the end of the late afternoon transition. This result is consistent with the results obtained by Darbieu et al. (2015) and Nilsson et al. (2016). The authors have shown the existence of a "pre-residual layer" at altitude 

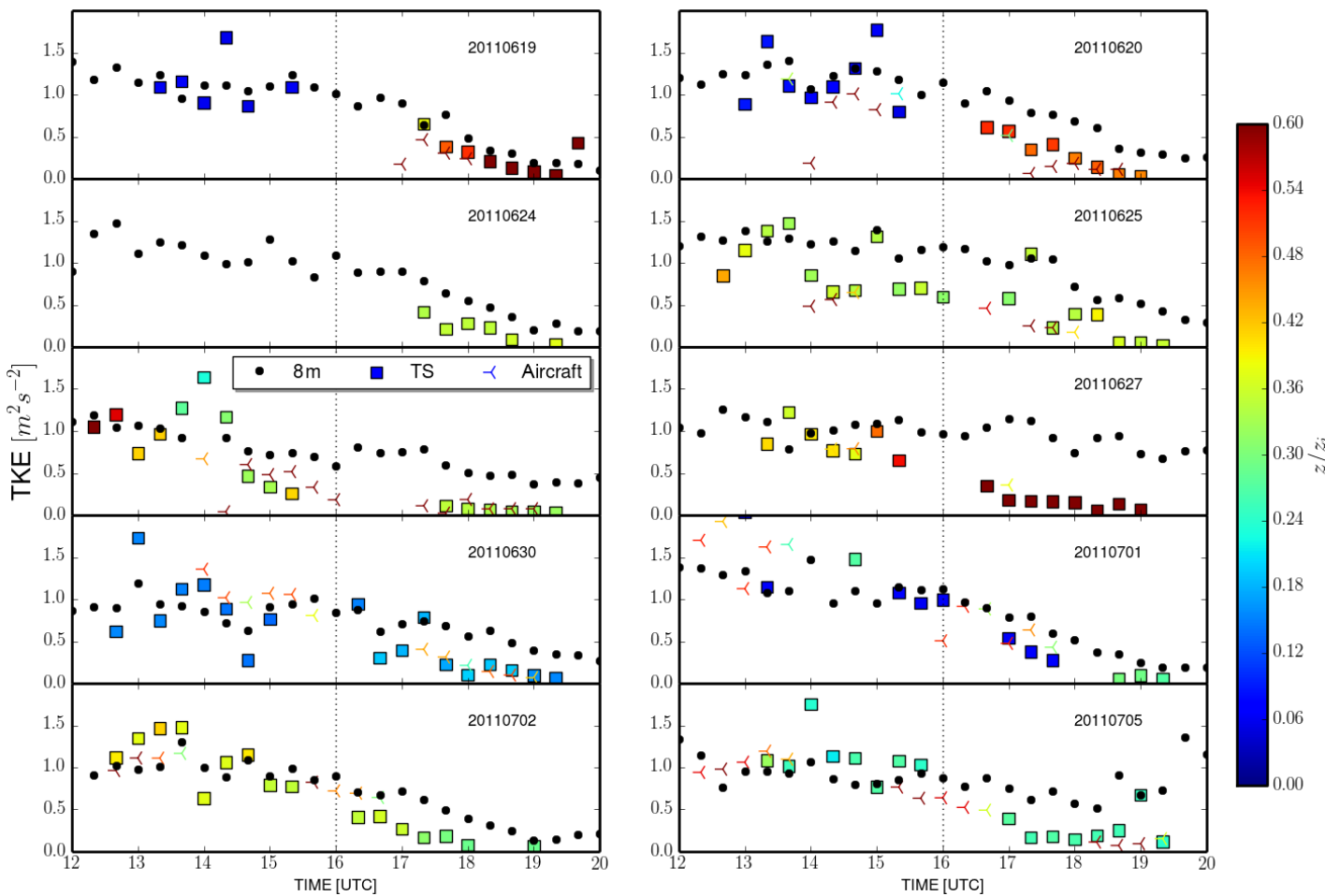

Figure 9. Time evolution of the turbulent kinetic energy measured from $(\square)$ the turbulence tethered sonde (o), the $8 \mathrm{~m}$ tower and the $(\prec)$ aircraft during 10 IOPs. The colour is function of $z / z i$.

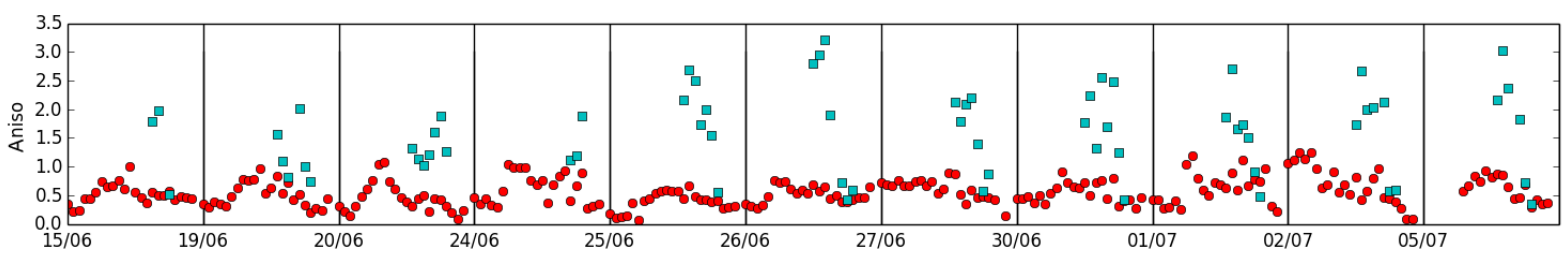

Figure 10. Time evolution of the anisotropy ratio measured by tethered balloon (cyan squares) and $8 \mathrm{~m}$ tower (red dots). The altitude of the tethered balloon is between 200 and $400 \mathrm{~m}$.

characterised by a decay of the TKE which is initiated first at altitude.

\subsection{Anisotropy of the turbulence}

One of the focuses of the BLLAST project is the vertical structure of the turbulence properties in the boundary layer. The anisotropy of turbulence is of particular interest during the afternoon transition (Darbieu et al., 2015; Couvreux et al., 2016).

Here, in order to estimate anisotropy, we define the ratio as

$A=\frac{3}{2} \frac{\overline{w^{\prime 2}}}{\mathrm{TKE}}$.

This is based on the fact that when turbulence is isotropic $\left(\overline{u^{\prime 2}}=\overline{v^{\prime 2}}=\overline{w^{\prime 2}}\right)$, TKE $=3 / 2 \overline{w^{\prime 2}}$ and $A=1$. The TKE can thus only be estimated from the variance of $w$. When $A=3$, the contribution of horizontal wind fluctuation to the TKE is zero $\left(\overline{u^{\prime 2}}=v^{\prime 2}=0\right)$ and the turbulence is mainly due to vertical wind fluctuations. When $A=0$, the vertical contribution to the TKE is zero $\left(w^{\prime 2}=0\right)$ and the horizontal wind fluctuations are the main contributor to the TKE.

Figure 10 presents the time evolution of the ratio estimated by Eq. 4 calculated by the sonic anemometer at $8 \mathrm{~m}$ (Nilsson et al., 2016) and by the TS at a higher altitude (see Table 4). For all the IOPs, values are larger than 1 at higher altitude than close to the surface, which means that the contribution of the horizontal motion is small. At low altitude ( $8 \mathrm{~m}$ in the figure), but also at 30,45 and $60 \mathrm{~m}$ (not shown here), the contribution between horizontal and vertical motion is more equivalent. At the end of the day, the values are similar between measurements at altitude and close to the surface. The evolution of the anisotropy ratio obtained with 
Table 4. Characteristics of the different TS flights; $z / z i$ is the ratio between the altitude and the top of the boundary layer.

\begin{tabular}{lrrrr}
\hline Day & $\begin{array}{r}\text { Start } \\
\text { time }\end{array}$ & $\begin{array}{r}\text { End } \\
\text { time }\end{array}$ & $\begin{array}{r}\text { Altitude of } \\
\text { flight }(\mathrm{m})\end{array}$ & $z_{*}$ \\
\hline 15 June 2011 & $14: 56$ & $16: 52$ & 200 & 0.2 \\
& $18: 15$ & $18: 50$ & 400 & 0.4 \\
19 June 2011 & $13: 15$ & $15: 50$ & 150 & 0.1 \\
& $17: 20$ & 2010 & 500 & 0.5 \\
20 June 2011 & $13: 00$ & $16: 00$ & 150 & 0.1 \\
& $16: 45$ & $19: 50$ & 500 & 0.5 \\
24 June 2011 & $17: 15$ & $19: 00$ & 250 & 0.4 \\
25 June 2011 & $12: 45$ & $16: 25$ & 300 & 0.4 \\
& $17: 00$ & $19: 45$ & 250 & 0.5 \\
26 June 2011 & $12: 30$ & $17: 00$ & 350 & 0.4 \\
& $17: 10$ & $20: 00$ & 250 & 0.5 \\
27 June 2011 & $13: 30$ & $16: 00$ & 400 & 0.4 \\
& $16: 45$ & $19: 45$ & 350 & 0.9 \\
30 June 2011 & $12: 40$ & $15: 25$ & 300 & 0.2 \\
& $16: 20$ & $19: 50$ & 400 & 0.2 \\
1 July 2011 & $13: 10$ & $14: 30$ & 200 & 0.1 \\
& $14: 50$ & $15: 30$ & 200 & 0.2 \\
2 July 2011 & $12: 30$ & $15: 30$ & 400 & 0.4 \\
& $16: 30$ & $19: 45$ & 350 & 0.3 \\
5 July 2011 & $13: 45$ & $16: 45$ & 300 & 0.3 \\
& $17: 30$ & $20: 00$ & 300 & 0.3 \\
\hline
\end{tabular}

TS is in agreement with the results from Darbieu et al. (2015) obtained with large eddy simulation models for one IOP of the BLLAST campaign. The authors also show that the contribution of the vertical velocity variance contribute to the TKE is larger in the middle than in the upper and lower parts of the PBL, due to small vertical velocity variance close to the surface and in the entrainment zone and larger shear at the interfaces.

Values of $A$ show the anisotropy of turbulence in the middle of the ABL in convective conditions. This is an important issue when, for instance, one wants to estimate the TKE while only $\overline{w^{\prime 2}}$ is measured (for example with a vertically pointing doppler lidar; Gibert et al., 2011).

This section demonstrates the interest in the observations made by TS, which allows continuous exploration of the middle of the boundary layer during the transition phase. Synergy with other traditional tools (aircraft and tower) allows the study of turbulent processes between the surface and the top of the boundary layer as shown in Fig. 8.

\section{Conclusions}

In this paper, we presented a new system for the estimation of turbulent transfer in the boundary layer as well as the associated first measurements. The system consists of a lightweight $(<2 \mathrm{~kg})$ turbulence probe based on a three-dimensional sonic anemometer suspended below a tethered balloon and cou- pled to an inertial motion sensor. These measurements have been evaluated by comparing turbulent measurements derived from a tower, aircraft and remotely piloted aircraft systems. Large correlation coefficients are obtained (systematically higher than 0.8 ) between the tower and TS measurements despite an unavoidable horizontal offset and an altitude difference during the convective period during the day. This innovative sensor has several advantages compared to more traditional turbulence measurements:

- The turbulence is estimated in the lower part of the PBL at altitudes where research aircraft encounter some difficulties in terms of flying but which is also higher than towers.

- With this TS system, measurements in the boundary layer can be made frequently and inexpensively.

- It complements a fixed-point tower, aircraft and/or new sensors embedded in RPASs in the framework of future field campaigns.

The only limitation for the deployment of this platform is that moderate wind $\left(<12 \mathrm{~ms}^{-1}\right)$ conditions are required. We have demonstrated that the turbulence sonde is capable of measuring heat and momentum fluxes using the direct eddycovariance method. For the first time, this new instrumental platform was used to measure heat flux and TKE. It was shown that it is possible to characterise different sorts of vertical motion occurring in the middle of PBL. After this first validation we are considering exploring the possibility of estimating continuous vertical profiles of the dissipation rate of the TKE by maintaining a slow descending rate during the profile and using a moving average over a given time period. We would also like to load off the system to add a fast humidity sensor such as a KH2O Krypton (Campbell Scientific Ltd) in order to simultaneously measure turbulent latent heat flux with the turbulent sensible heat flux. Another option worth exploring would be the simultaneous deployment of the system with other instruments (e.g. particle counter, $\mathrm{O}_{3}-\mathrm{CO}_{2}$ probes, droplets) to better understand the link between microphysics and atmospheric turbulence such as in fog.

\section{Data availability}

The data used in this study are freely available from the BLLAST (2016) database: http://bllast.sedoo.fr/database.

Acknowledgements. The authors would like to thank F. Said for providing the tower measurements. The BLLAST field experiment was made possible thanks to the contribution of several institutions and sources of support: INSU-CNRS (Institut National des Sciences de l'Univers, Centre National de la Recherche Scientifique, LEFE-IMAGO program), Météo-France, Observatoire Midi-Pyrénées (University of Toulouse), EUFAR 
(European Facility for Airborne Research), BLLATE-1 \& 2, and COST ES0802 (European Cooperation in the field of Scientific and Technical). The field experiment could not have been made possible without the contribution of all participating European and American research groups, all of whom have contributed to a significant degree. The Piper Aztec research airplane was operated by SAFIRE, a unit supported by INSU-CNRS, Météo-France and the French Spatial Agency (CNES). The BLLAST field experiment and the 2010 campaign were hosted at the Centre de Recherches Atmosphériques, on the Pyrenean Platform for Observation of the Atmosphere P2OA (http://p2oa.aero.obs-mip.fr). P2OA facilities and staff are funded and supported by the University Paul Sabatier, Toulouse, France, and CNRS (Centre National de la Recherche Scientifique).

Edited by: E. Pardyjak

Reviewed by: two anonymous referees

\section{References}

André, J. C., De Moor, G., Lacarrere, P., Therry, G., and du Vachat, R.: Modeling the 24-hour evolution of the mean and turbulent structure of the planetary boundary layer, J. Atmos. Sci., 35, 1861-1883, 1978.

Angevine, W. M., Bakwin, P. S., and Davis, K. J.: Wind profiler and RASS Measurements compared with measurements from a 450-m-tall tower, J. Atmos. Ocean. Tech., 15, 818-825, 1998.

Aubinet, M., Vesala, T., and Papale, D.: Eddy covariance. A Practical Guide to Measurement and Data Analysis, Edition Springer Atmospheric Science, the Netherlands, 438, ISBN 978-94-0072351-1, 2012.

Balsley, B. B.: The CIRES Tethered Lifting System: a survey of the system, past results and future capabilities, Acta Geophys., 56, 21-57, doi:10.2478/s11600-007-0045-z, 2008

Belušic, D., Lenschow, D. H., and Tapper, N. J.: Performance of a mobile car platform for mean wind and turbulence measurements, Atmos. Meas. Tech., 7, 1825-1837, doi:10.5194/amt-71825-2014, 2014.

BLLAST: BLLAST dataset, available at: http://bllast.sedoo.fr/ database, last access: 6 September 2016.

Couvreux, F., Bazile, E., Canut, G., Seity, Y., Lothon, M., Lohou, F., Guichard, F., and Nilsson, E.: Boundary-layer turbulent processes and mesoscale variability represented by numerical weather prediction models during the BLLAST campaign, Atmos. Chem. Phys., 16, 8983-9002, doi:10.5194/acp-16-89832016, 2016.

Darbieu, C., Lohou, F., Lothon, M., Vilà-Guerau de Arellano, J., Couvreux, F., Durand, P., Pino, D., Patton, E. G., Nilsson, E., Blay-Carreras, E., and Gioli, B.: Turbulence vertical structure of the boundary layer during the afternoon transition, Atmos. Chem. Phys., 15, 10071-10086, doi:10.5194/acp-1510071-2015, 2015.

Gibert, F., Arnault, N., Cuesta, J., plougonven, R., and Flamant, P.: Internal gravity waves convectively forced in the atmospheric residual layer during the morning transition, Q. J. Roy. Meteor. Soc., 137, 1610-1624, 2011.

Janicot, S., Thorncroft, C. D., Ali, A., Asencio, N., Berry, G., Bock, O., Bourles, B., Caniaux, G., Chauvin, F., Deme, A., Kergoat, L.,
Lafore, J.-P., Lavaysse, C., Lebel, T., Marticorena, B., Mounier, F., Nedelec, P., Redelsperger, J.-L., Ravegnani, F., Reeves, C E., Roca, R., de Rosnay, P., Schlager, H., Sultan, B., Tomasini, M., Ulanovsky, A., and ACMAD forecasters team: Large-scale overview of the summer monsoon over West Africa during the AMMA field experiment in 2006, Ann. Geophys., 26, 25692595, doi:10.5194/angeo-26-2569-2008, 2008.

Kaimal, J. C. and Businger, J. A.: A continuous wave sonic anemometer-thermometer, J. Clim. Appl Meteorol., 2, 156-164, 1963.

Kaimal, J. C. and Gaynor, J. E.: Another look at sonic thermometry, Bound.-Lay. Meteorol., 56, 401-410, doi:10.1007/BF00119215, doi:10.1007/BF00119215, 1990.

Kaimal, J. C., Wyngaard, J. C., Haugen, D. A., Coté, O. R., and Izumi, Y.: Turbulence structure in the convective boundary layer, J. Atmos. Sci., 33, 2152-2169, 1976

Lapworth, A. J. and Mason, P. J.: The New Cardington BalloonBorne Turbulence Probe System, J. Atmos. Ocean. Technol., 5, 699-714, 1988.

Lenschow, D. H.: Aircraft measurements in the boundary layer, American Meteorological Society, Boston, MA, USA, 39-55, 1986.

Lenschow, D. H. and Stankov, B. B.: Model of the height variation of the turbulence kinetic energy budget in the unstable planetary boundary layer, J. Atmos. Sci., 31, 465-474, 1974.

Lenschow, D. H. and Stankov, B. B.: Length scales in the convective boundary layer, J. Atmos. Sci., 43, 1198-1209, 1986.

Lenschow, D. H. and Stephens, P. L.: The role of thermals in the convective boundary layer, Bound.-Lay. Meteorol., 19, 509-532, 1980.

Lothon, M., Lohou, F., Pino, D., Couvreux, F., Pardyjak, E. R., Reuder, J., Vilá-Guerau de Arellano, J., Durand, P., Hartogensis, O., Legain, D., Augustin, P., Gioli, B., Lenschow, D. H., Faloona, I., Yagüe, C., Alexander, D. C., Angevine, W. M., Bargain, E., Barrié, J., Bazile, E., Bezombes, Y., Blay-Carreras, E., van de Boer, A., Boichard, J. L., Bourdon, A., Butet, A., Campistron, B., de Coster, O., Cuxart, J., Dabas, A., Darbieu, C., Deboudt, K., Delbarre, H., Derrien, S., Flament, P., Fourmentin, M., Garai, A., Gibert, F., Graf, A., Groebner, J., Guichard, F., Jiménez, M A., Jonassen, M., van den Kroonenberg, A., Magliulo, V., Martin, S., Martinez, D., Mastrorillo, L., Moene, A. F., Molinos, F., Moulin, E., Pietersen, H. P., Piguet, B., Pique, E., RománCascón, C., Rufin-Soler, C., Saïd, F., Sastre-Marugán, M., Seity, Y., Steeneveld, G. J., Toscano, P., Traullé, O., Tzanos, D., Wacker, S., Wildmann, N., and Zaldei, A.: The BLLAST field experiment: Boundary-Layer Late Afternoon and Sunset Turbulence, Atmos. Chem. Phys., 14, 10931-10960, doi:10.5194/acp14-10931-2014, 2014.

Martin, S., Beyrich, F., and Bange, J.: Observing Entrainment Processes Using a Small Unmanned Aerial Vehicle: A Feasibility Study, Bound.-Lay. Meteorol., 150, 449-467, doi:10.1007/s10546-013-9880-4, 2014.

Miller, D., Tong, C., and Wyngaard, J.: The Effects of Probe-Induced Flow Distortion on Velocity Covariances: Field Observations, Bound.-Lay. Meteorol., 91, 483-493, doi:10.1023/A:1001868030313, 1999.

Morris, A. L., Call, D., and McBeth, R. B.: A small tethered balloon sounding system., B. Am. Meteorol. Soc., 56, 964-969, 1975. 
Muschinski, A., Frehich, R., Jensen, M., Hugo, R., Hoff, A., Eaton, F., and Balsley, B.: Fine-Scale Measurements Of Turbulence In The Lower Troposphere: An Intercomparison Between A Kite- And Balloon-Borne, And A Helicopter-Borne Measurement System, Bound.-Lay. Meteorol., 98, 219-250, doi:10.1023/A:1026520618624, 2001.

Nilsson, E., Lohou, F., Lothon, M., Pardyjak, E., Mahrt, L., and Darbieu, C.: Turbulence kinetic energy budget during the afternoon transition - Part 1: Observed surface TKE budget and boundary layer description for 10 intensive observation period days, Atmos. Chem. Phys., 16, 8849-8872, doi:10.5194/acp-16-88492016, 2016.

Ogawa, Y. and Ohara, T.: Observation of the turbulent structure in the planetary boundary layer with a Kytoon-Mounted ultrasonic anemometer system, Bound.-Lay. Meteorol., 22, 123-131, 1982.

Saïd, F., Canut, G., Durand, P. Lothon, M., and Lohou, F.: Seasonal evolution of boundary-layer turbulence measured by aircraft during the AMMA 2006 Special Observation Period, Q. J. Roy. Meteor. Soc., 136, 47-65, 2010.

Stull, R. B.: An introduction to Boundary Layer Meteorology, vol. new edition 1999, Kluwer Academic Publishers, Dordrecht, the Netherlands, 666 pp., 1988.

Utall, T., Curry, J. A., McPhee, M. G., Perovich, D. K., Moritz, R. E., Maslanik, J. A., Guest, P. S., Stern, H. L., Moore, J. A., Turenne, R., Heiberg, A., Serreze, M. C., Wylie, D. P., Persson, O. G., Paulson, C. A., Halle, C., Morison, J. H., Wheeler, P. A., Makshtas, A., Welch, H., Shupe, M. D., Intrieri, J. M., Stamnes, K., Lindsey, R. W., Pinkel, R., Pegau, W. S., Stanton, T. P., and Grenfeld, T. C.: Surface heat budget of the arctic ocean, B. Am. Meteorol. Soc., 83, 225-275, 2002.
Weckwerth, T., Parsons, D. B., Koch, S. E., Moore, J. A., Demoz, B. B., Flamant, C., Geers, B., Wang, J., and Feltz, W. F.: An overview of the international $\mathrm{H}_{2} \mathrm{O}$ project (IHOP_2002) and some preliminary highlights, B. Am. Meteorol. Soc., 85, 253277, 2004.

Wildmann, N., Ravi, S., and Bange, J.: Towards higher accuracy and better frequency response with standard multi-hole probes in turbulence measurement with remotely piloted aircraft (RPA), Atmos. Meas. Tech., 7, 1027-1041, doi:10.5194/amt-7-1027-2014, 2014.

Wulfmeyer, V., Behrendt, A., Bauer, H., Kottmeier, C., Corsmeier, U., Blyth, A., Craig, G., Schumann, U., Hagen, M., Crewell, S., Di Girolamo, P., Flamant, C., Miller, M., Montani, A., Mobbs, S., Richard, E., Rotach, M., Arpagaus, M., Russchenberg, H., Schlüssel, P., König, M., Gärtner, V., Steinacker, R., Dorninger, M., Turner, D., Weckwerth, T., Hense, A., and Simmer, C.: The Convective and Orographically-induced Precipitation Study: A Research and Development Project of the World Weather Research Program for improving quantitative precipitation forecasting in low-mountain regions., B. Am. Meteorol. Soc., 89, 14771486, 2008. 